\title{
Psychological impacts of Intimate Partner Violence on women
}

\section{Sarmad Muhammad Soomar}

Sigma Theta Tau International and Aga Khan University, School of Nursing and Midwifery

\section{Abstract}

Women are considered safe at home but many of us become intentionally unaware about the situation that Intimate Partner Violence is a harsh and unacceptable behavior that itself is exhibited by one's own loving partner, thus making the home surroundings unsafe for women. Among all sort of violence shown by intimate partner, Physical is relatively obvious but other kinds are common too. Reasons involved behind these types of behaviors are multifactorial ranging from inequality, patriarchy and dowry to disobedience, infertility and Husbands with borderline personalities. These reasons ultimately create big disasters in women's life physically, socially and mentally. Majority of the impacts exhibited in women's life are psychological. Thus, the paper aims to highlight some major impacts of Intimate partner violence on women specially on psychological wellbeing like Depression, Posttraumatic stress disorder and Suicide, with the support of relevant literature and author's witnessed case scenario. On the basis of literature review, recommendations provided includes prevention, support, marital counseling, women's education, better health facilities for women and many others. Intimate partner violence is very common and harmful. As women are more vulnerable so these circumstances impact them at a greater extent.

\section{Key words}

Intimate partner violence, Psychological impacts, Depression, Suicide and Posttraumatic Stress Disorder

\section{Introduction}

Home is considered as the safest place anywhere in the world. People living within the home are always there to help and protect each other. But what happens when the terror lies within the house itself. One becomes anxious and fearful of home. One always thinks of being far from it or escape to become safe. In my opinion, Intimate Partner Violence (IPV) is the action, which itself is a terror or fear that lies within home. This erupts from the roots of one's own relationships. It begins with a loud roar and ends up with almost a pint of blood.

IPV is a current and common issue in Pakistani society. It is a major community health and socio cultural issue which is impacting mental health of individuals as well (Ali, Mogren \& Krantz, 2013). IPV is an abusive, harsh and non-tolerable attitude; physical, verbal or sexual from own spouse or loving (intimate) partner including both homosexual and heterosexual. People experiencing IPV can be nonsexual intimate partners as well like dating or cohabiting couples (Centers of Disease Control and Prevention [CDC], 2015). Around the globe married women are the major victims of IPV. Specifically in Pakistani context other sorts of relationship are less common and incidences with men are under reported due to shame and pride (Hassan \& Malik, 2012; White \& Satyen, 2015).

Violence displayed by intimate partners could be of various natures. The most common categories exhibited are Physical, Sexual, Emotional and
Financial. All the four distributions are connected with each other. Physical IPV is relatively obvious in comparison to other kinds and this actually leads to increase in other sorts of violence as well. It usually begins with slapping, punching or hitting and can be increased to a great extent causing lethal outcomes like fractures, injuries or even death. Sexual IPV is a kind which encompasses all sexual assaults committed forcefully by the dominant partner (culprit) on the other spouse (victim) without their will. Emotional abuse can be verbal or nonverbal. It is displayed through making the spouse guilty or anxious with continuous and unnecessarily complaining. Cursing them or pointing minute fumbles in their actions to show them that they lack confidence and competence. It is a sort of psychological torture through hurting one's feelings. Lastly Financial, which is defined as having a control on the recessive spouse's economic prospects like salaries, funds, savings or even restricting them from perusing educational and employment opportunities (University of Southern California [UCS], 2015).

IPV is commonly growing issue in developing countries. Especially in Pakistan the matter has increased by the pace of time. A recent study shows that since marriage the rate of all sorts of IPV is more than $80 \%$ in Pakistan (Qayyum, 2013). According to Ali, Abbas \& Ather (2014) Physical and Sexual IPV is most prevalent in our context and other types are relatively less exhibited. The lifetime prevalence for physical IPV is $57.6 \%$ and for sexual IPV is $54.5 \%$. So 
we can predict that up to what extent it is increasing and how it is impacting on victim's health ranging from physical, sexual and most importantly psychological wellbeing (CDC, 2015).

\section{Case Scenario}

During a community home visit I witnessed a case of a 32 years old female, Para 1 and Gravida 3. On taking history I came to know that she had an ectopic pregnancy and one abortion in past. On investigating further about the abortion, she verbalized about her husband's aggressive behavior and suspicious nature. After a long and sensitive discussion she further disclosed that it is usual for her husband to beat and curse her. It actually resulted in these deadly consequences and she lost her baby. Furthermore, she described that the reasons for cursing or beating her are not genuine always. Sometimes it depends on his (husband) mood; sometimes he displaces his stress on her (wife) or occasionally he doubts her (wife) honesty in the relationship, without any reason. She also discussed that his poor impulse control results in showing aggressive behavior so she becomes the victim in almost every situation.

\section{Discussion}

Referring to above witnessed scenario, IPV exhibited in majority of the households has different reasons behind it. It seems to me that gender inequality, social prejudice, fear from the culprit, helplessness and financial constrains could be possible reasons behind the existence of these types of behaviors in our socio cultural context. Ali et al. (2011) has considered gender inequality as a leading reason of IPV especially in countries like Pakistan. Furthermore, it describes that the status of women in Asian context is minor or lower in comparison to men because of patriarchal traditions.

Other reported reasons for incidences of IPV includes dowry issues, disobedience, inability of women to have children especially male child, low socio economic status and husband's habit of drug addiction (Ali \& Bustamante-Gavino, 2007). Male spouse having border line personality disorder (BPD) also has a strong association in IPV perpetration (Jackson, Sippel, Mota, Whalen \& Schumacher, 2015). Continuous experience of IPV poses impacts on overall health and wellbeing of women, ranging from Physical health, Social wellbeing and psychological health mainly. Physical issues resulted due to IPV are related with huge increase in deaths, trauma, casualties, overall poor health, chronic pain and disabilities (Plichta, 2004). Reproductive health problems are also faced by women experiencing violence from spouse like infections, unwanted pregnancies and induced abortions (Laanpere, Ringmets, Part \& Karro, 2012). Violence faced during pregnancy also has adverse obstetric outcomes (Howard, Oram, Galley, Trevillion \& Feder, 2013). Moreover, women's social functioning is deprived because of IPV in many cases (Hassan \& Malik, 2012). Majority of the reported impacts of facing IPV are psychological. These impacts on mental health indirectly affect other aspects of health too. According to Ali, Morgen \& Krantz (2013) women going through the disaster of IPV most commonly report presence of suicidal thoughts, feeling of being worthless and facing problems while making judgments and decisions. Other studies suggest that women who are victimized of IPV may exhibit decrease in confidence, high levels of nervousness or anxiety, inhibition of sexual activity and problems with appetite (Ulloa, Hammett, Guzman \& Hokoda, 2015). Furthermore, it is considered that there is a strong association of depression with IPV (White \& Satyen, 2015; Devries et al., 2013). Victims repeatedly facing beating, slapping, abusive language or deadly injuries due to harsh attitude of loving partner or spouse are at higher risks of developing Posttraumatic Stress Disorder (PTSD) and usually they have less chances of recovery or growth after these type of painful events (Kunst, Winkel \& Bogaerts, 2010).

Encountering IPV for a long period of time leads the victim to harmful psychological consequences listed above. Most common psychological effects are discussed in detail below:

Depression

People of different age groups, many a times in their lives have experienced being sad or not happy with their present conditions. This is usually common, but when these feelings start affecting a person's daily routine, productivity and simply the way of living, that is something really serious. This is what actually the victim faces, when they are being humiliated by their life partners often or may be daily. Studies have been evident that depression resulted from IPV is frequently observed among various cultures around the world (White \& Satyen, 2015). Increased episodes of violence, escalates the risk of depressive symptoms in women (Johnson, Giordano, Longmore \& Manning, 2014; Devries et al., 2013). Women exposed to IPV have severe feelings of depression. Their frame of mind switches to pessimism, guilt, worthlessness, irritability, decreased energy and sleep, low moods, decreased 
concentration and feeling of loneliness (National Institute of Mental Health [NIMH], 2015).

\section{Posttraumatic Stress Disorder (PTSD)}

According to Tramayne (2012) encountering

IPV is a traumatic event for women or the victims, which may lead to dangerous impacts or potential disorders like Posttraumatic Stress Disorder (PTSD). PTSD is featured by a marked anxiety after experiencing or witnessing any painful (traumatic) event. People experiencing such events face symptoms mostly when they recall that event or experience it once again. Symptoms of PTSD primarily includes intense fear, shortness of breath, sweating, night mares, sleeping difficulties, dizziness, cramps, issues with daily routine, feeling of harming self, depression and problems with handling relationships. Women's mental health is really affected in regard to IPV, as they start getting the above symptoms of PTSD. These may worsen when women are repeatedly victimized and thus, the post traumatic recovery becomes slower in that condition (Kunst, Winkel \& Bogaerts, 2010).

\section{Suicide}

Suicidal ideation or attempt is also a serious result of IPV. Survivors of IPV are at higher risk of having suicidal thoughts or attempting to harm one's own self multiple times (Clay, 2014). Finding from researches show that Pakistani women; who were abused physically, emotionally or verbally by their husbands are more likely to plan or commit suicidal acts (Haqqi, 2008).

\section{Recommendations}

Prevention is the foremost intervention in controlling or reducing this behavior. It will be anticipated through pre-marital counseling, where both the partners are advocated to respect each one's dignity and pride along with the encouragement of care and affection in marital relations. Parents of the bride should be recommended to bravely support their daughters, in case they face any sort of abuse or violence from their spouse. Parents should keep the doors open for daughters even after their marriage, so they feel free to approach them when they face any misery in their marital bonds. Traditions of dividing properties among children should also be seen. As girls are granted with less or almost none portion of inherited property, it becomes difficult for them to survive in case their spouse, parents and in laws do not favor them. Women's education and employment is also a good tool to overcome this issue. Males should be taught about gender sensitization from the grass route levels in order to support and understand their spouse and the relationship. Medical facilities like clinics, staff, ambulances and on call helplines, should be readily available in order to manage casualties and emergencies of IPV. Nurses should work effectively to help the victims, through keeping their assessments honest and stronger to overcome issues rising from IPV. All medical staff should deal clients or victims of IPV within the medical ethics by portraying nonjudgmental attitude and maintaining confidentiality of the particular case. Maintenance, review and proper application of legislatives policies regarding women's right and violence should be taken into consideration. More shelter homes and rehabilitation centers must be establish by the government and different NGOs, that should be safe and secure for the survival of abused, homeless women or especially IPV victims with all facilities for their Physical, Social and Psychological recovery.

Conclusion

In conclusion, Intimate partner violence is a leading community health problem everywhere in the world. Women are more prone to this, in comparison to other victims. Violence from own spouse has multiple causes behind it. The incidences of IPV also leads to different effects on the victim's complete state of health. Especially it has more serious impacts on mental health of the victims which can seriously fluctuate one's complete wellbeing. In order to overcome this issue everyone has to collectively fight so that the incidences lower down with the interval of time and the society becomes violence free.

References

- Ali, T. S., Abbas, A., \& Ather, F. (2014). Associations of controlling behavior, physical and sexual violence with health symptoms. Journal of Women's Health Care, 3(6). Retrieved from http://dx.doi.org/10.4172/2167-0420.1000202

- Ali, T. S., Mogren, I., \& Krantz, G. (2013). Intimate partner violence and mental health effects: a population-based study among married women in Karachi, Pakistan. International journal of behavioral medicine, 20(1), 131-139.

- Ali, T. S., Krantz, G., Gul, R., Asad, N., Johansson, E., \& Mogren, I. (2011). Gender roles and their influence on life prospects for women in urban Karachi, Pakistan: a qualitative study. Global health action, 4.

- Ali, T. S., \& Bustamante-Gavino, I. (2007). Prevalence of and reasons for domestic violence among women from low socioeconomic 
communities of Karachi. Eastern Mediterranean Health Journal, 13(6), 1417-1426.

- Centers of Disease Control and Prevention. (2015). Intimate partner violence. Retrieved from http://www.cdc.gov/violenceprevention/intimate partnerviolence/index.html

- Clay, R. A. (2014). Suicide and intimate partner violence. $\quad$ Retrieved from http://www.apa.org/monitor/2014/11/suicideviolence.aspx

- Devries, K. M., Mak, J., Bacchus, L. J., Child, J. C., Falder, G., et al. (2013) Intimate Partner Violence and Incident Depressive Symptoms and Suicide Attempts: A Systematic Review of Longitudinal Studies. PLoS Med 10(5): e1001439. doi:10.1371/journal.pmed.1001439.

- Haqqi, S. (2008). Suicide and Domestic Violence: Could There Be a Correlation? The Medscape Journal of Medicine, 10(12), 287.

- Hassan, S., \& Malik, A. A. (2012). Psycho-social correlates of Intimate partner violence. Pakistan Journal of Psychological Research, 27(2), 279-295. Retrieved from http://www.pjprnip.edu.pk/pjpr/index.php/pjpr/a rticle/view/199/169

- Howard, L. M., Oram, S., Galley, H., Trevillion, K., \& Feder, G. (2013) Domestic Violence and Perinatal Mental Disorders: A Systematic Review and MetaAnalysis. PLoS Med 10(5): e1001452. doi:10.1371/journal.pmed.1001452

- Jackson, M. A., Sippel, L. M., Mota, N., Whalen, D., \& Schumacher, J. A. (2015). Borderline personality disorder and related constructs as risk factors for intimate partner violence perpetration. Aggression and Violent Behavior, 24, 95-106.

- Johnson, W. L., Giordano, P. C., Longmore, M. A., \& Manning, W. D. (2014). Intimate partner violence and depressive symptoms during adolescence and young adulthood. Journal of Health and Social Behavior, 55(1), 39-55.

- Kunst, M. J. J., Winkel, F. W. \& Bogaerts S. (2010). Posttraumatic Growth Moderates the Association between violent revictimization and persisting PTSD symptoms in victims of Interpersonal violence: Journal of Social and Clinical Psychology, 29 (5), 527-545.

- Laanpere, M., Ringmets, I., Part, K., \& Karro, H. (2012). Intimate partner violence and sexual health outcomes: a population-based study among 16-44year-old women in Estonia. European Journal of Public Health, 23(4), 688-693.

- National Institute of Mental Health. (2015). Depression. Retrieved from https://www.nimh.nih.gov/health/topics/depressi on/index.shtml\#part_145394

- Plichta, S. B. (2004). Intimate partner violence and physical health consequences: policy and practice implications. Journal of Interpersonal violence, 19(11), 1296-1323.

- Qayyum, K. (2013). Domestic violence against women: prevalence and men's perception in PGRN districts of Pakistan. Retrieved from http://www.rutgerswpfpak.org/content/pdfs/repo rts/DV-report.pdf

- Tramayne, S. (2012). Intimate partner violence as a risk factor for PTSD in female survivors of domestic violence: A Meta-Analysis. Dissertations Loyola eCommons. Retrieved from http://ecommons.luc.edu/cgi/viewcontent.cgi?arti cle $=1315 \&$ context=luc_diss

- Ulloa, E. C., Hammett, J. F., Guzman, M. L., \& Hokoda, A. (2015). Psychological growth in relation to intimate partner violence: A review. Aggression and Violent Behavior. Retrieved from http://dx.doi.org/10.1016/j.avb.2015.07.007

- University of Southern California. (2015). Violence against women coalition. Retrieved from http://www.usc.edu/dept/education/vawc/intam ate-partner-violence/types.html

- White, M. E., \& Satyen, L. (2015). Cross-cultural differences in intimate partner violence and depression: A systematic review. Aggression and Violent Behavior, 24, 120-130. 